\title{
Process Optimization and Physico-Chemical Evaluation of Apple Ginger Blended Wine along with Different Sweetening Agents
}

\author{
Shivani Jyoti, Naveet Kaushal and Amrinder Singh*
}

${ }^{I}$ Department of Agriculture, Institute of Engineering and Technology, Ropar, Punjab, India ${ }^{2}$ Department of Agriculture, Mata Gujri College, Sri Fatehgarh Sahib, Punjab, India

${ }^{3}$ Department of Agriculture, Desh Bhagat University, Mandi, Gobindgarh, Punjab, India

*Corresponding author

\section{A B S T R A C T}

Keywords

Apple, Ginger,

Wine, Sugar,

Honey, Stevia,

Saccharomyces

cerevisiae var.

ellipsoideus

Article Info

Accepted:

18 December 2020

Available Online:

10 January 2021
Preparation of wine from surplus apple fruits can reduces postharvest losses besides source of income. Apple ginger wine using different sources of sugars i.e. honey, sugar and stevia to raise the TSS of must to $20^{\circ} \mathrm{B}$ was prepared as per routine procedure. To impart medicinal value, ginger was added with different concentration to the must. The apparent effect of addition of extract was to delay the fermentation, not to stop it. The effect fermented conditions to fermented juice aroma compounds was also analyzed using headspace solid- phase microextraction and gas chromatograph- mass spectrometry (HSSPME-GC-MS).Volatile aroma compounds were detected of apple juice, yeast and fermented juice. Physico-chemical characteristics of apple ginger wine before and after fermentation showed that the addition of extract did not affect the quality of wine adversely. From the sensory quality point of view, the extract treated with $6 \%$ ginger juice and sugar at $20^{\circ} \mathrm{Bwas}$ superior to the $8 \%$ ginger juice with $20^{\circ} \mathrm{B}$ (only stevia) in most of the sensory qualities. The highest score (9) was awarded to $6 \%$ ginger juice at $20^{\circ} \mathrm{B}$ (only sugar) based wine. The total phenols which are expected to contribute the antimicrobial and antioxidant activities of the wine. Reducing sugars, total sugar, titrable acidity, ethanol and volatile acidity increased significantly while total phenols decreased.

\section{Introduction}

Apple (Malus domestica) is a prominent fruit and is a member of the Rosaceae family, one of the most widely cultivated trees. Apple a highly delicious temperate fruit but due to its perishable nature, it has to be either stored or processed. The major apple growing states in India are Jammu and Kashmir, Himachal Pradesh and Uttaranchal (Sharma, 1994). It is a major horticultural produce and is the backbone of the rural economy of these States (Agrahari and Khurdiya, 2003). However, during the last 4-5 years, cultivation of apples has been extended to North East Himalayan States also. Most of the production of this fruit is used for table purposes but a portion is being processed into various products (Kaushal andJoshi, 1995). The composition of apple pomace with respect to its fiber content viz sugar, cellulose, hemicelluloses, pectin and roughage appears to have the best 
proposition for incorporation in the bakery industry for production of high fibre baked foods. The crude fibre content of apple pomace is approximately $14-30 \%$ of the dry weights. Apple fibre is higher in TDF (Total Dietary Fibres) than wheat and oat bran. It has good water holding capacity and act as humectants in certain food products. Apple fibre has been incorporated into cookies, granola bars and muffins to produce high fibre bakery products. Use of apple pomace has been made through fermentation into several product including citric acid, ethanol, pigment etc.

The role of yeast in the fermentation of sugars into alcohol and carbon dioxide has been known for more than two centuries (Anderson, 1989). Spontaneous fermentation can bring satisfactory results in the form of a wine with an interesting, rich taste and aroma. In the initial phase, the wild yeasts produce large amounts of glycerol and aromatic substances but do not guarantee the proper course of fermentation and they significantly increase volatile acidity, in contrast to selected noble yeasts. Spontaneous fermentation cannot be conducted at a temperature below $15^{\circ} \mathrm{C}$; there are also often problems with the fermentation of musts with a higher concentration of sugars. Selected yeast strains are available on the market and they ferment sugars with the production of ethanol and compounds responsible for the desired bouquet, without creating harmful byproducts. Using them, fermentation can be conducted in a specific, intended manner, obtaining liquor with the required parameters and doing so in a repeatable fashion, which is important for the industry.

Ginger (Zingiber officinale Rosc.) is commonly called 'Ale' or 'Adrak' which is an important commercially grown crop for its aromatic rhizomes which are used as a spice, condiment and as a medicine. Ginger has many biological and medicinal properties. It is used in pharmacology because of low toxicity. Ginger is antitumor, antioxidant, anti-inflammatory, anti apoptotic, cytotoxic, antiproliferative and antiplatelet activities (Young et al., 2005). Thus wine stimulates the release of digestive enzymes, which digest not only alcohol but many other nutrients found in wine. Ginger has many health benefits, so the proposed work will be focused on the preparation of good quality of wine from ginger, honey and sugar blend by using baker's yeast. Honey was used in the ginger wine due to many reasons. According to National Honey Board, honey contains sugars like fructose $(38.2 \%)$, glucose $(31 \%)$ and water $(17.1 \%)$ which make it suitable substrate for fermentation. Mead is the honey wine prepared by different fermentation technology.

The food industry uses a variety of preservation and processing, methods to extend the shelf life of fruits and vegetables such that they can be consumed year round and transported safely to consumers all over the world, not only those living near the growing region. Therefore, utilization of ripe fruits or their juices for wines production is considered to be an attractive means of utilizing surplus and over-ripen fruits. Moreover, fermentation helps to preserve and enhance the nutritional value of foods and beverages. The present study was designed to accomplish the fortification process of fermented apple mash, enological properties during the aging process and sensory and nonsensory characters of the prepared product ( 9 point hedonic scale).

\section{Materials and Methods}

\section{Raw material}

Apple fruits of cultivar Golden Delicious were obtained from the fruit orchard, Solan. 
Fruits were washed followed by grading and the juice was extracted with the help of hydraulic press. The juice was then, filtered with the help of a muslin cloth and pasteurized in crown corked bottles for further use. Ginger were collected from the local market of Sirhind, Fatehgarh Sahib. Ginger was washed and juice was extracted, filtered, pasteurized and stored in crown corked bottles. Honey, sugar, and stevia used to ameliorate the apple must for the studies were procured locally.

\section{Yeast culture}

The yeast culture viz. Saccharomyces cerevisiae var. ellipsoideus, used in the study was originally obtained from the Department of Microbiology, Punjab Agriculture University, Ludhiana.

\section{Inoculum preparation}

The inoculum was prepared by inoculating the slant culture into $10 \mathrm{ml}$ test tube incubated overnight then $3 \%$ inoculum transferred to $100 \mathrm{ml}$ of the sterile GYE broth medium taken in $250 \mathrm{ml}$ flask and grown it on a rotary shaker for $48 \mathrm{~h}$. After incubation period the culture was used for preparation of wine.

\section{Preparation of ginger juice extraction}

The ginger extract was prepared by removing the skin and washing, followed by crushing in the mixer.

Preparation of must: Apple juice was used to prepare apple must and its TSS was raised to $20^{\circ} \mathrm{B}$ by the addition of sugar syrup, honey and stevia depending upon the treatment. Ginger extracts as outlined earlier were added into the must at different concentration to each treatment. Musts were kept overnight before being inoculated with the active yeast culture.

\section{Fermentation}

Fermentation was initiated by addition of active yeast culture of $S$. cerevisiae var. ellipsoideus @ 5\% at a temperature of $28 \pm 1^{\circ} \mathrm{C}$. When no further loss in TSS took place, the fermentation was considered as complete. Bubbling was started in the glass jar during fermentation. It was followed by siphoning and filtration. All the wines were racked initially after every fifteen days and then after one month. During fermentation, fall in TSS $\left({ }^{\circ} \mathrm{B}\right)$, titratable acidity and ethanol concentration of extracts were monitored. Based on the results, the concentration of extract that would not affect fermentability and physico-chemical characters were worked out. After the completion of fermentation, the wines were siphoned/ racked and kept for maturation in glass bottles.

\section{Physico-chemical analysis of wine}

The $\mathrm{pH}$ and TSS content of wine were determined as per the method of (AOAC, 2002). The $\mathrm{pH}$ was measured by $\mathrm{pH}$ meter (Model Li120, Elico) and the TSS was measured from the same sample by placing few drops of it on the prism of refractometer (Atago Co., Tokyo, Japan) and the direct reading was taken as described in (AOAC, 2002).

\section{Biochemical analysis of wine}

Titratable acidity was measured by titration method cited by (Ranganna, 1995). Total sugar was measured by phenol - sulphuric acid method of (Dubois et al., 1956) using glucose as standard. Reducing sugars were estimated by the method of (Miller, 1972). The Phenols were estimated by (Malik et al., 1980)[12]. Volatile acidity was measured by method of (Amerine et al., 1980) and (AOAC, 2002). Quantity of ethanol and fermentation efficiency was estimated by 
spectrophotometric method (Caputi et al., and Wright, 1969).

\section{Determination of volatile aroma compounds}

Volatiles from apple juice and fermented drinks were extracted using solid phase microextraction (SPME). $5 \mathrm{ml}$ of juice were weighed in a $20 \mathrm{ml}$ headspace vial and capped with a septum. SPME extraction. A divinylbenzene/carboxen/polydimethylsiloxan e (DVB/Car/PDMS) fiber (Supelco Inc., Bellefonte, PA, USA) was used for headspace SPME sampling. SPME parameters were: incubation time $30 \mathrm{~min}$, extraction temperature $22 \pm 2^{\circ} \mathrm{C}$, extraction duration 30 min, desorption $15 \mathrm{~min}, 250^{\circ} \mathrm{C}$. For the analysis of the SPME extracts, a Perkin Elmer Clarus $500 \mathrm{GC} / \mathrm{MS}$ and a Elite-Wax ETR (60 $\mathrm{m} \times 0.25 \mathrm{~mm}$ i.d.; DF $0.25 \mathrm{~m}$ ) was used. Working conditions were: injector $250^{\circ} \mathrm{C}$; transfer line to $\mathrm{MSD} 260^{\circ} \mathrm{C}$; oven temperature start $50^{\circ} \mathrm{C}$, hold $2 \mathrm{~min}$, programmed from 50 to $100{ }^{\circ} \mathrm{C}$ at $5^{\circ} \mathrm{C}$ min- 1 hold $5 \mathrm{~min}$, and from 100 to $210^{\circ} \mathrm{C}$ at $5^{\circ} \mathrm{C}$ min-1, hold $15 \mathrm{~min}$; carrier gas $(\mathrm{He}) 1 \mathrm{ml} \mathrm{min-1;} \mathrm{split} \mathrm{ratio} \mathrm{2:1;}$ ionization EI+; acquisition parameters in full scan mode: scanned m/z 50-300. Compounds were identified by comparison of their mass spectra with mass spectral libraries (Nist98), and by calculation of linear retention indexes and comparison with literature data. All analyses were performed in triplicate. As a quantitative measure, the share in the total GC peak area for each compound is given.

\section{Statistical analysis}

The differences in the volatile profiles during fermentation were analyzed using the analysis of variance (ANOVA) procedure of SPSS, Version 17.0. HSD Tukey's test was applied to compare the mean values of the volatile compounds of different fermentation conditions. p-value at 0.05 was used to determine the significant differences of content of volatiles in fermented juice samples. Mean values with standard deviations are reported.

\section{Sensory evaluation}

The sensory analysis of different wines was conducted by a panel of 10 semi trained judges. The sensory evaluation report reveals that the apple ginger blended wine was clean and golden brown colour. In terms of the total score the wine has been evaluated as of superior quality.

\section{Treatments}

\begin{tabular}{|c|c|}
\hline Treatments & Treatment Combinations \\
\hline $\mathbf{T}_{\mathbf{0}}$ & Untreated apple juice \\
\hline $\mathbf{T}_{1}$ & $4 \%$ ginger juice + Only Honey $\left(20^{\circ} \mathrm{B}\right)$ \\
\hline $\mathbf{T}_{2}$ & $4 \%$ ginger juice + Only Sugar $\left(20^{\circ} B\right)$ \\
\hline $\mathbf{T}_{3}$ & $4 \%$ ginger juice + Only Stevia $\left(20^{\circ} \mathrm{B}\right)$ \\
\hline $\mathbf{T}_{4}$ & $4 \%$ ginger juice + Sugar and Honey $\left(20^{\circ} \mathrm{B}\right)$ \\
\hline $\mathbf{T}_{5}$ & $6 \%$ ginger juice+ Only Honey $\left(20^{\circ} \mathrm{B}\right)$ \\
\hline $\mathbf{T}_{6}$ & $6 \%$ ginger juice+ Only Sugar $\left(20^{\circ} \mathrm{B}\right)$ \\
\hline $\mathbf{T}_{7}$ & $6 \%$ ginger juice+ Only Stevia $\left(20^{0} \mathrm{~B}\right)$ \\
\hline $\mathbf{T}_{8}$ & $6 \%$ ginger juice + Sugar and Honey $(20 \circ \mathrm{B})$ \\
\hline $\mathbf{T}_{9}$ & $8 \%$ ginger juice + Only Honey $(20 \circ \mathrm{B})$ \\
\hline $\mathbf{T}_{10}$ & $8 \%$ ginger juice + Only Sugar $(20 \circ B)$ \\
\hline $\mathbf{T}_{11}$ & $8 \%$ ginger juice + Only Stevia $(20 \circ B)$ \\
\hline $\mathbf{T}_{12}$ & $8 \%$ ginger juice + Sugar and Honey $(20 \circ \mathrm{B})$ \\
\hline
\end{tabular}




\section{Results and Discussion}

\section{Composition analysis}

Total soluble solids, $\mathrm{pH}$, and alcohol content are reported in table 1.The total soluble solids of the sample were showed significantly more utilization of total sugar. This might be due to the elimination of acetic acid bacteria and inhibitory substances which delayed fermentation and under utilized of sugar (Grossmann and Becker, 1984). In the present study, Brix of the best fermented sample $\mathrm{T}_{6}$ was $5.80^{\circ} \mathrm{B}$. Alcohol content of the best fermented sample $\mathrm{T}_{6} \mathrm{was} 5.70 \%$. The total sugar content were $8.15 \%$ and reducing sugar was $6.02 \%$ as shown in table 1 . Total sugar content also decreased due to the ethanol fermentation by $S$. cerevisiae (Budak and Guzel- Seydim, 2010). The maximum ethanol production was recorded 2.69 and fermentation efficiency was $92 \%$ in the best treatment $\mathrm{T}_{6}$.

\section{Phenolic profile}

A significant decrease in total phenol was observed during fermentation as shown in fig.1. The maximum decrease showed in the best treatment $\mathrm{T}_{6}$ i.e. $2.45 \%$. Decrease in phenol content may be due to complexion of phenol with proteins and their polymerization and subsequent precipitation as observed (Sonia et al., 1980).

\section{Total Antioxidant Content of the blended wine}

\section{Aromatic profile of apple juice (Control)}

An overview of the results of the aroma analysis of the apple ginger juices is given in Tables 2. Totally seven volatile compounds (total peak AU 2999, 93×10 $)$ were detected in juice, (namely)- 4 esters (1 acetates, 1 hexanoates, 1 butanoate, 1 propanoate), 1 alcohols, 2 aldehydes. Apple ginger blended juice aroma is mainly composed of aldehydes $(60,5 \%)$ and esters $(35 \%)$. The main volatile compounds are 2-hexenal (50,1\%), 1 butanol, 2- methyl acetate $(13,1 \%)$ and hexanal $(10,5 \%)$. These aldehydes have been described as the main contributors to the green odour of apple fruit and apple juice (Zheng et al., 2004).

Table.1 Physico- chemical analysis for the different blended patterns

\begin{tabular}{|c|c|c|c|c|c|c|}
\hline Treatments & $\mathbf{p H}$ & $\begin{array}{c}\mathbf{T S S} \\
\left({ }^{\circ} \mathbf{B}\right)\end{array}$ & $\begin{array}{c}\text { Total sugar } \\
(\mathbf{\%})\end{array}$ & $\begin{array}{c}\text { Reducing } \\
\text { sugar } \\
(\mathbf{\%})\end{array}$ & $\begin{array}{c}\text { Ethanol } \\
\text { content } \\
(\mathbf{\%} / \mathbf{v})\end{array}$ & $\begin{array}{c}\text { Fermentation } \\
\text { Efficiency } \\
(\mathbf{\%})\end{array}$ \\
\hline $\mathbf{T}_{\mathbf{0}}$ & 3.17 & 6.00 & 6.05 & 0.21 & 3.50 & 60 \\
\hline $\mathbf{T}_{\mathbf{1}}$ & 2.26 & 5.18 & 6.91 & 5.78 & 6.99 & 61 \\
\hline $\mathbf{T}_{\mathbf{2}}$ & 2.11 & 5.63 & 7.94 & 5.83 & 7.17 & 85 \\
\hline $\mathbf{T}_{\mathbf{3}}$ & 2.47 & 5.05 & 6.88 & 5.67 & 3.35 & 53 \\
\hline $\mathbf{T}_{\mathbf{4}}$ & 2.17 & 5.60 & 6.94 & 5.82 & 7.11 & 75 \\
\hline $\mathbf{T}_{\mathbf{5}}$ & 2.29 & 5.17 & 6.90 & 5.76 & 6.94 & 60 \\
\hline $\mathbf{T}_{\mathbf{6}}$ & 2.06 & 5.80 & 7.95 & 5.84 & 7.21 & 92 \\
\hline $\mathbf{T}_{\mathbf{7}}$ & 2.43 & 5.00 & 6.87 & 5.66 & 3.54 & 51 \\
\hline $\mathbf{T}_{\mathbf{8}}$ & 2.19 & 5.33 & 6.93 & 5.82 & 7.07 & 62 \\
\hline $\mathbf{T}_{\mathbf{9}}$ & 2.33 & 5.13 & 6.89 & 5.72 & 6.90 & 60 \\
\hline $\mathbf{T}_{\mathbf{1 0}}$ & 2.14 & 5.63 & 7.92 & 5.82 & 7.15 & 80 \\
\hline $\mathbf{T}_{\mathbf{1 1}}$ & 2.38 & 5.00 & 6.86 & 5.65 & 3.62 & 48 \\
\hline $\mathbf{T}_{\mathbf{1 2}}$ & 2.22 & 5.27 & 6.92 & 5.81 & 7.03 & 64 \\
\hline
\end{tabular}


Table.2 Total antioxidant content of the apple ginger wine

\begin{tabular}{|c|c|c|c|c|c|}
\hline Compounds & $\begin{array}{l}\text { Apple juice } \\
\text { (Control) }\end{array}$ & Yeast & $T_{6}\left(8^{\text {th }}\right.$ day $)$ & $T_{2}\left(28^{\text {th }}\right.$ day $)$ & $T_{10}\left(8^{\text {th }}\right.$ day $)$ \\
\hline \multicolumn{6}{|l|}{ Acids } \\
\hline Acedic acid & n.d. & $151.71 \pm 1.78$ & $91.36 \pm 1.19 \mathrm{a}$ & $252.38 \pm 2.18 b$ & $95.40 \pm 2.58 \mathrm{a}$ \\
\hline 2-methyl propanoic acid & n.d. & $51.63 \pm 1.39$ & n.d. & n.d. & n.d. \\
\hline 4 methyl pentanoic acid & n.d. & $49.46 \pm 0.78$ & n.d. & n.d. & n.d. \\
\hline octanoic acid & n.d. & n.d. & $59.20 \pm 1.97 \mathrm{a}$ & $182.46 \pm 0.47 \mathrm{~b}$ & $59.52 \pm 2.68 \mathrm{a}$ \\
\hline n-decanoic acid & n.d. & n.d. & $31.17 \pm 0.15$ & n.d. & $26.11 \pm 1.19$ \\
\hline$\%$ & & 27.4 & 1.4 & 3.1 & 1.6 \\
\hline \multicolumn{6}{|l|}{ Esters } \\
\hline ethyl acetic ester & n.d. & n.d. & $240.69 \pm 11.40 \mathrm{a}$ & $271.45 \pm 6.69 \mathrm{~b}$ & $219.32 \pm 15.48 \mathrm{a}$ \\
\hline $\begin{array}{l}\text { acetic acid 2-methylbutyl } \\
\text { ester }\end{array}$ & n.d. & n.d. & $645.5 \pm 31.17 \mathrm{ab}$ & $683.13 \pm 1.58 b$ & $613.02 \pm 23.38 \mathrm{a}$ \\
\hline $\begin{array}{c}\text { acetic acid 2-methylbutyl } \\
\text { ester }\end{array}$ & $394.43 \pm 10.13$ & n.d. & n.d. & n.d. & n.d. \\
\hline \multicolumn{6}{|l|}{ Compounds } \\
\hline acetic acid butylester & $202.24 \pm 11.07$ & n.d. & n.d. & n.d. & n.d. \\
\hline $\begin{array}{c}\text { acetic acid } \\
\text { hexylesterpentafluoropropin } \\
\text { oic acid }\end{array}$ & $216.14 \pm 8.70$ & n.d. & $1042.30 \pm 7.66 \mathrm{c}$ & $977.16 \pm 17.66 \mathrm{~b}$ & $670.22 \pm 8.07 \mathrm{a}$ \\
\hline Hexyl ester & $237.90 \pm 12.66$ & n.d. & n.d. & n.d. & n.d. \\
\hline hexanoic acid ethyl ester & n.d. & n.d. & $1416.71 \pm 21.58$ & n.d. & $689.46 \pm 15.65$ \\
\hline hexanoic acid hexylester & n.d. & n.d. & n.d. & $906.47 \pm 14.53$ & n.d. \\
\hline octanoic acid, ethyl ester & n.d. & n.d. & $1023.25 \pm 58.23 \mathrm{a}$ & $2327.84 \pm 10.91 \mathrm{~b}$ & $990.23 \pm 50.09 \mathrm{a}$ \\
\hline decanoic acid ethyl ester & n.d. & n.d. & $460.84 \pm 9.69 \mathrm{a}$ & $864,81 \pm 8.91 \mathrm{~b}$ & $287.11 \pm 11.32 \mathrm{a}$ \\
\hline $\begin{array}{l}\text { undecanoic acid ethyl ester } \\
\text { 9-Decenoic acid, ethyl }\end{array}$ & n.d. & n.d. & $81.56 \pm 4.44$ & n.d. & $31.88 \pm 2.15$ \\
\hline $\begin{array}{c}\text { Ester acetic acid 2- } \\
\text { phenylethyl }\end{array}$ & n.d. & n.d. & $50.82 \pm 0.76$ & n.d. & $20.09 \pm 0.80$ \\
\hline Ester & n.d. & n.d. & $14.88 \pm 0.45$ & n.d. & $20.64 \pm 0.72$ \\
\hline$\%$ & 35.0 & n.d. & 31.0 & 42.8 & 30.9 \\
\hline \multicolumn{6}{|l|}{ Alcohols } \\
\hline 1-propanol, 2-methyl & n.d. & $41.12 \pm 0.56$ & n.d. & n.d. & n.d. \\
\hline 1-hexanol, 2-ethyl & n.d. & $50.70 \pm 1.28$ & n.d. & n.d. & n.d. \\
\hline 1-hexanol & n.d. & n.d. & $246.79 \pm 5.39$ & $273.20 \pm 0.71$ & $226.93 \pm 159.96$ \\
\hline 2-hexen-1-ol & $133.29 \pm 8.04$ & n.d. & n.d. & n.d. & n.d. \\
\hline $\begin{array}{c}2- \\
\text { hydroxyethylhydrazine/4- } \\
\text { penten-2-ol }\end{array}$ & n.d. & $138.75 \pm 2.32$ & n.d. & n.d. & n.d. \\
\hline 2-hydroxyethylhydrazine & n.d. & n.d. & $5590.48 \pm 39.31$ & $5167.67 \pm 86.63$ & $4972.39 \pm 204.62$ \\
\hline 1-butanol, 3-methyl & n.d. & $381.51 \pm 11.3$ & $1772.79 \pm 57.55$ & $1874.57 \pm 6.99$ & $2259.75 \pm 52.27$ \\
\hline 8-heptadecanol & n.d. & n.d. & n.d. & $60.12 \pm 1.36$ & \\
\hline phenylethyl alcohol & n.d. & $58.73 \pm 0.72$ & $126.37 \pm 3.91$ & $257.64 \pm 0.68$ & $287.95 \pm 14.20$ \\
\hline$\%$ & 4.4 & 57.6 & 60.0 & 54.1 & 67.5 \\
\hline \multicolumn{6}{|l|}{ Aldehydes } \\
\hline Hexanal & $313.59 \pm 12.25$ & n.d. & n.d. & n.d. & n.d. \\
\hline 2-hexenal & $1502.34 \pm 73.67$ & n.d. & n.d. & n.d. & n.d. \\
\hline$\%$ & 60.5 & n.d. & n.d. & n.d. & n.d. \\
\hline
\end{tabular}


Fig.1 Change in the phenol content of the must during fermentation

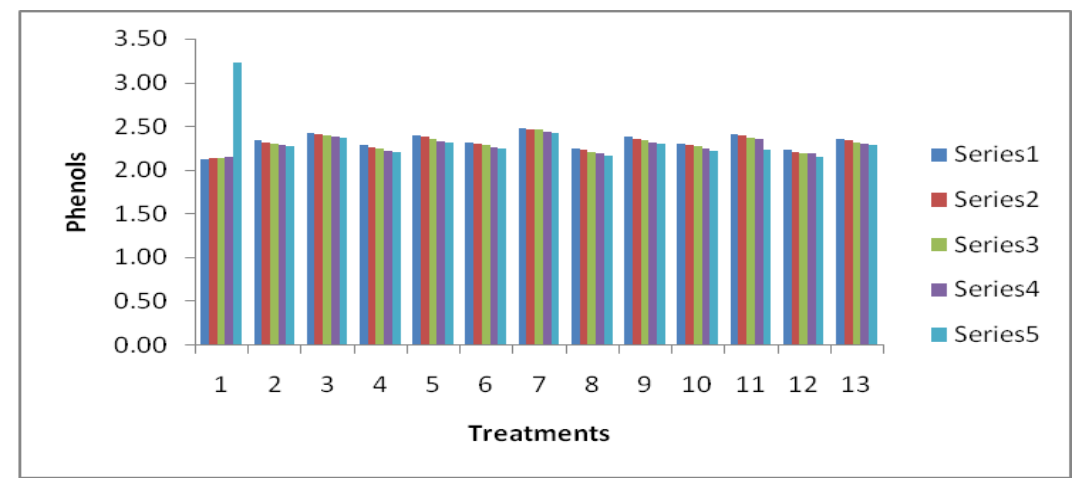

Aromatic profile of the apple ginger wine

Out of the twelve treatments, $\mathrm{T}_{6}$ stood best followed by $T_{2}$ and $T_{10}$ so these 3 samples were investigated for their aromatic profile. Three sources of aroma compounds in fermented juices - apple juice, yeast, and yeast metabolites -were analysed. Some compounds - aldehydes hexanal and 2hexenal and alcohols 2-hexen-1-ol - found in apple juice were not possible to identified in fermented apple juices. A total of 16 volatile compounds were detected in fermented juice at the early stage of fermentation 13 at the 28 day of fermentation. In the majority of juices alcohols (67, 5\%), esters (31\%) and acids $(1,6 \%)$ were detected after 8th day of fermentation and alcohols $(54,1 \%)$, esters $(42,8 \%)$ and acids $(3,2 \%)$ after 28th day of fermentation. The main groups of compounds that forms the fermentation bouquet are the acids, alcohols and esters and, to a lesser extent, aldehydes and ketones (Lambrechts and Pretorius, 2000). Acetic acid, phenylethyl alcohol and 3-methyl-1-butanol, were characteristic compounds of yeasts. Among higher alcohols determined, all the strains produced 3- methyl-1-butanol that is the major higher alcohol in wine (Romano et al., 2008). 3-methyl-1 butanol and 2-methyl-1butanol also plays the major role in the apple juices quality. Both substances are notgenuine constituents of the apple fruit, but are inevitably formed during apple juice production, probably through transamination and decarboxylation of the amino acids leucine and isoleucine, respectively (Hey et al., 2007) n-decanoic acid, hexanoic acid ethylester, decanoic acid ethylester, 9Decenoic acid, ethyl ester were detected after 8th day of fermentation, but were not detected after 28th day of fermentation.

\section{Sensory evaluation}

Wines prepared from different treatments were evaluated for their sensory parameters by panel of ten judges on 9 point hedoni scale. The score for color and appearance, taste, aroma, mouth feel and overall acceptability were given out of 9. Out of twelve treatments highest score was given to the best treatment $\mathrm{T} 6$.

In conclusion the present study mainly focused on the process monitoring of wine during fermentation period. The experimental investigation was aimed to study the variation in each parameter during fermentation period. The final analysis of wine of various parameters- alcohol content, $\mathrm{pH}$ was conducted. The study concluded that $\mathrm{pH}$ that followed a decreasing trend in treatment $\mathrm{T}_{6}$. The sugar content of wine were decrease with the increase in the no. of days in treatment $\mathrm{T}_{6}$. With the reduction in the total sugar alcohol content was increased in treatment $\mathrm{T}_{6}$. The phenol content was decreased with increasing 
in no. of days in treatment $\mathrm{T}_{6}$. However, all the samples were found to be acceptable prepared from apple and ginger extract. It is concluded that addition of ginger extract and different sweetening agents improved the physico-chemical characteristics as well as sensory quality of wine and produce good quality of wine.

\section{References}

1. Agrahari, P.R., and Khurdiya, D.S. 2003. Studies on preparation and storage of RTS beverage from pulp of culled apple pomace. Indian Food Packer 57(2):5661.

2. Amerine, M.A., Berg, H.A. Kunkee, R.E. Ough, C.S. Singleton, V.L. and Webb,A.D. (1980)Technology of Wine Making. $4^{\text {th }}$ edn. Westport Connecticut: AVI Publishing Co Inc, p. 794.

3. Anderson, R.J., 1989. Yeast and Victorian brewer: incidents and personalities in the search for the true ferment. Journal of institute of brewing 95:337-345.

4. A.O.A.C. 2002. Official Methods of Analysis. $16^{\text {th }}$ Edition.Association of Official Analytical Chemists, Washington D.C. USA.

5. Budak, H.N., and Güzel-Seydim, Z. 2010. Antioxidant activity and phenolic content of wine vinegars produced by two different techniques. Journal of Science Food Agriculture90: 2021-2026.

6. Caputi, A., and Wright. 1969. Collaboration study for the determination of ethanol in wine by chemical oxidation. Journal Association of official Analytical Chemists52:85.

7. Dubois, M., Gilles, K.A. Hamilton, J.K. Rebers, P.A. and Fred Smith. 1956. Determination of sugars and related substances. Application of analytical chemistry28(3): 350-356.

8. Grossman, M.K., and Becker, R. 1984.
Studies on bacterial problems in wine fermentation. Kellelwirtschaft10: 272275.

9. Hey, M., Kürbel, P. Hopf, I. and Dietrich, H. 2007. Untersuchungsort enreiner Apfelsaftaromen. FlüssigesObst, 02: 6267.

10. Kaushal, N.K., Joshi, V.K. 1995. Preparation and evaluation of apple pomace based cookies. Indian Food Packer 49(5):17-24.

11. Lambrechts, M. G., and I.S. Pretorius. 2000. Yeast and its importance to wine aroma. South African Journal of Enology and Viticulture 21:97-129.

12. Malik, E.P., and Singh, M.B. 1980. Plant Enzymology and Hittoenzymology

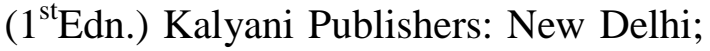
286.

13. Miller, G.L. 1972. Use of dinitrosalicylic acid reagent for determination of reducing sugar. Journal of Annual Chemistry 31: 426-428.

14. Ranganna, S., 1995. Handbook of Analysis and Quality Control for fruit and vegetable products. $2^{\text {nd }}$ Edn.pp 1112.Tata Mc. Graw Hill Pub.Co.Ltd., New delhi, India.

15. Romano, P., Capece, A. Serafino, V. Romaniello, R. Poeta, C. 2008. Biodiversity of wild strains of Saccharomyces cerevisiae as tool to complement and optimize wine quality. World Journal of Microbiology and Biotechnology 24: 1797-1802.

16. Sharma, V.K., 1994. SevKeUpiyogitaSev Utpadanaur Sanrakashan. Him Publication of Shimla p1-32.

17. Sonia, A., Ballesteres, Chirife, J. Juan, P. and Bozzini. 1980. Antibacterial effects and cell morphological changes in Sfaphylococcus aureus subjected to low ethanol concentration Journal of Food Science58(2): 435-438.

18. Young, H.Y., Lou, Y.L. Cheng, H.Y. Hsieh, W.C. Lia, J.C. Peng, W.H. 2005. 
Analgesic and anti- inflammatory activities of gingerol. Journal of Ethnopharmacol. 96 (1-2): 207-10.

19. Zeng, C.H., Kim, T.H. Kim, K.H. Leem, Y.H. and Lee, H.J. 2004. Characterization of potent aroma compounds in Chrysanthemum coronarium L. (Garland) using aroma extraction dilution analysis. Flavour and fragrance journal19: 401-405.

\section{How to cite this article:}

Shivani Jyoti, Naveet Kaushal and Amrinder Singh. 2021. Process Optimization and PhysicoChemical Evaluation of Apple Ginger Blended Wine along with Different Sweetening Agents. Int.J.Curr.Microbiol.App.Sci. 10(01): 2941-2949.

doi: https://doi.org/10.20546/ijcmas.2021.1001.340 